\title{
Las técnicas escultóricas de reproducción como medio de integración para alumnado con discapacidad
}

\author{
Sculpture reproduction techniques as a means to the integration of \\ disabled pupils
}

Jose Javier ÁNGELES. Escuela de Artes de Cuenca Jose María Cruz Novillo (España). joseangelesescultor@gmail.com

Resumen: El siguiente artículo es una descripción interpretativa de una experiencia basada en la realización de un taller de técnicas de reproducción escultórica a partir de moldes de alginato, dirigido al alumnado con necesidades educativas especiales del Programa Específico de Formación Profesional Básica (PEFPB), realizado en un instituto de enseñanza secundaria. Se ha llevado a la práctica una metodología de interacción colectiva, monitorizada por los profesores del centro, en la que se ha empleado alginato dental como material para la confección de moldes, el cual, al ofrecer unas cualidades de copia excepcionales, permite al alumnado experimentar de manera manipulativa y visual todos los cambios que la materia comprende desde el proceso de mezcla de polvo y agua hasta la obtención de la reproducción.

Las introducciones y explicaciones impartidas han sido simplificadas para obtener una mejor lectura y comprensión por parte del alumnado, introduciendo como ejemplo imágenes de obras escultóricas obtenidas mediante este procedimiento artístico. Además, se han realizado pequeñas demostraciones previas a la actividad para que el alumnado analice de forma visual cómo se manipula la materia, planteando como objetivo la reproducción de su propia mano en escayola.

Cuando los conceptos y lenguajes artísticos se adaptan a las capacidades y necesidades del alumnado, hacen del aula un lugar de integración y cooperación, en el que los alumnos se introducen en experiencias visuales y manipulativas con las que descubren nuevos mecanismos de expresión.

Palabras clave: integración, discapacidad, escultura, alginato, moldes, autoestima. 


\begin{abstract}
The following article is an interpretative description of a workshop devoted to sculpture reproduction based on alginate moulds addressed to students with special educational needs within the Specific Programme of Basic Vocational Training at a secondary education high-school. This workshop, supervised by teachers at the high-school, was performed following an interactional collective approach and using dental alginate for the production of moulds. Offering exceptional reproduction features, this material allowed the students to participate in a sensorial experience by means of the observation of all the changes that it suffers; from the mixing of alginate powder and water to the composition of the reproduction itself.
\end{abstract}

Theinstructionsandexplanationsgivenweresimplified toobtainabetterunderstanding of the students. Different images showing examples of sculpture works obtained by means of this technique were also provided. I addition, prior demonstrations were carried out so that the students could visually analyse how the material should be handled, suggesting the making of a plaster reproduction of their own hands.

When concepts and artistic languages meet the student's needs and capacities, they make the classroom a place for integration and cooperation where students live sensorial experiences which help them discover new ways of expression.

Key words: integration, disability, sculpture, alginate, molds, self-esteem.

\title{
Introducción
}

La actividad se centra en el desarrollo de un taller artístico de técnicas escultóricas de moldeo con alginato y vaciado de escayola, llevado a cabo con alumnos del Programa Específico de Formación Profesional Básica (PEFPB) de alojamiento y lavandería del Instituto de Enseñanza Secundaria Los Cerros, en Úbeda (Jaén), en mayo de 2018. El alumnado está integrado por quince personas, siete chicos y ocho chicas, con discapacidades de nivel moderado leve. Una persona con deficiencia mental moderada es aquella que adquiere habilidades de comunicación durante la niñez, pudiendo acceder con supervisión a un puesto de trabajo y ocuparse en su día a día de su propio cuidado personal. En este grupo participan personas diagnosticas con síndrome de Down, síndrome de Prader Willi, hemiplejía, trastorno de espectro autista y discapacidad socio-intelectual, entendiéndose esta última como "noción general de discapacidad que centra su atención en la expresión de las limitaciones del funcionamiento individual dentro de un contexto social y representa una desventaja sustancial para el individuo." (Schalock, 2009, p. 22). Las personas con discapacidad y/o capacidades especiales necesitan una atención específica enfocada a sus habilidades cognitivas como la percepción, entendiéndola como la toma de contacto del individuo con el medio que le rodea; la atención, debido a una falta organizativa y respuesta a la información recibida; la memoria, como capacidad para organizar y recordar la información, y la metacognición, como la capacidad de reflexión sobre los procesos cognitivos. (Luckasson et al. 2002). 
Partiendo de esta base, se ha ideado una actividad grupal con el fin de promover la integración por medio de la interacción entre alumnado y profesorado, empleando como medio materiales de creación artística, tratándose además, de una experiencia novedosa para ellos.

\section{Metodología: investigación basada en las artes}

Para la realización de esta experiencia colaborativa en la que introducimos materiales y técnicas escultóricas, se ha llevado a cabo una metodología de interacción con las personas del aula, basada en la participación colectiva. Las informaciones verbales acerca del uso de materiales han sido simplificadas para reforzar la comprensión, siendo acompañadas en todo momento y a modo de documentación artística, con imágenes de ejemplos de otras figuras y esculturas realizadas por medio de vaciados del natural a partir de alginato dental.

La investigación basada en imágenes (Image Based Research) se centra en ofrecer a las personas participantes una narrativa visual de gran riqueza descriptiva. Las metodologías que emplean prioritariamente imágenes visuales son adecuadas para el desarrollo del aprendizaje artístico dentro y fuera de las aulas, favoreciendo la inclusión de los alumnos en un grupo de trabajo.

La actividad escultórica se adaptó a las necesidades y capacidades del alumnado, para promover la conexión grupal participativa, tanto de manera verbal como visual y manipulativa. Al final de la actividad, cada una de las personas que integran alumnado obtiene la reproducción de su propia mano en escayola.

\section{Motivo, planificación y procedimiento de la actividad}

Con motivo de la Semana Cultural del Instituto, celebrada todos los años en el mes de mayo en la que se realizan actividades conjuntas de índole cultural, (música, arte y literatura), la dirección del centro se puso en contacto con nosotros para la realización de un taller de artes plásticas dirigido al alumnado del Programa Específico de Formación Profesional Básica. Fue el departamento de actividades extraescolares del centro el que medió para proponer este taller enfocado al manejo de materiales para la creación artística. Evaluado el plan de trabajo, este taller se convierte en un proyecto de inclusión e integración para el alumnado del centro, dentro de las actividades programadas en la agenda de la Semana cultura.

En la edición anterior de la Semana Cultural, se realizó un taller bajo nuestra dirección, para el alumnado de $4^{\circ}$ de Educación Secundaria Obligatoria (ESO), basado en la confección de moldeo con alginato de sus manos para reproducirlas en escayola. Entre el alumnado estaba Celia, una niña de dieciséis años con síndrome de Down. Los objetivos planteados y los resultados obtenidos en esta actividad fueron tan motivadores y positivos para ella, que la dirección del departamento de 
actividades extraescolares, al ver como su capacidad de interacción e integración aumentaba para con el grupo, propuso este taller para el conjunto del alumnado del Programa Específico de Formación Profesional Básica (PEFPB). Por parte del centro se consideraba prioritario aumentar la autoestima del grupo, de modo que se planteó la elaboración de una adaptación de esta actividad artística, que al igual que en la edición anterior, los procesos de creación fueran novedosos y los resultados muy espectaculares, organizándola de manera que todas las personas del grupo consiguieran completar cada proceso y obtener un resultado final que fuese muy elaborado y sorprendente. De este modo se conseguiría reforzar la autoestima personal del grupo en cuanto a la consecución de sus objetivos de aprendizaje, considerando que la actividad sería muy útil para este alumnado en concreto.

Las técnicas de moldeo con alginato se basan en la mezcla de polvo (alginato) y agua a partes iguales. Esta mezcla produce un gel de textura viscosa que tan solo permanece en este estado entre dos y tres minutos. Transcurrido ese tiempo, comienza a endurecer hasta fraguar, obteniendo una goma rígida, que es la que cumple la función de molde. El alginato en estado de gel copia todos y cada uno de los detalles y formas del objeto o de la parte de nuestro cuerpo que introducimos en él, obteniendo un molde en el que ha quedado registrada la superficie, en este caso, la mano de cada alumno. Posteriormente, vertemos la escayola líquida en el interior del molde de alginato para obtener la reproducción exacta de nuestra mano. La peculiaridad de esta materia es su breve periodo de trabajabilidad y manipulación.

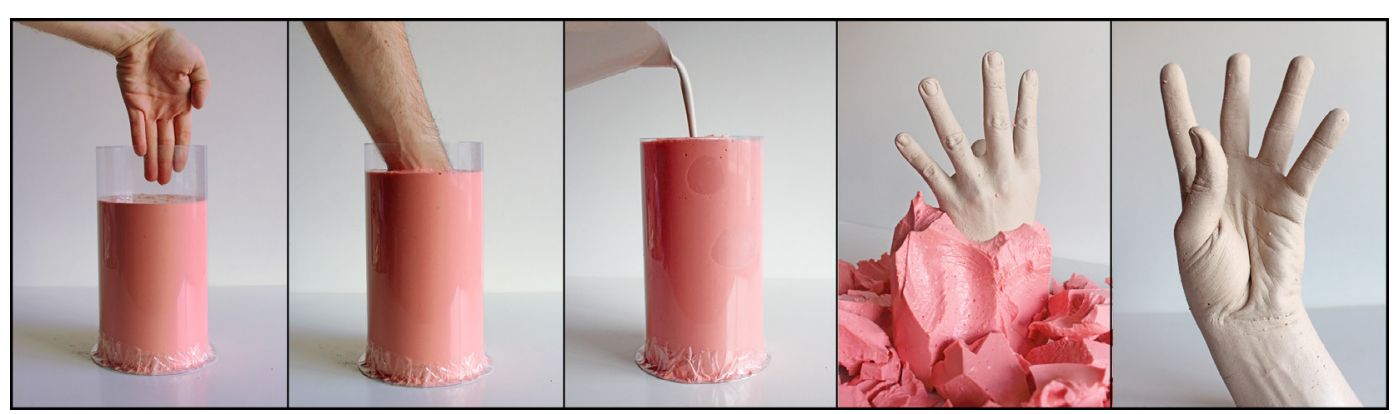

Figura 1. Ejemplo de fase de moldeo con alginato dental de una mano y su reproducción en escayola.

Se trata de un aprendizaje innovador fundamentado en el atractivo por la mímesis, en el que se producen transformaciones físicas y visuales de los materiales empleados para obtener una copia exacta de una mano o cualquier otro objeto. Las actividades plásticas basadas en la utilización del alginato para la confección de moldes se alejan de las prácticas comunes que suelen impartirse en el aula. Esta técnica, desarrollada por medio de la manipulación, ofrece procesos de experimentación en los que el alumnado puede observar cómo mezclando el alginato en polvo con agua se obtiene un gel muy viscoso, que en pocos minutos se convierte en una goma rígida que copia todas las texturas y formas de las superficies con las que tiene contacto. Ver es imitar y la imitación está llena de juegos. A su vez, el juego basado en la observación y la interacción con el medio que nos rodea, nos dirige a encontrar la mímesis (Delgado, 2015). 
El alginato es una materia que ofrece múltiples posibilidades experimentales gracias a la naturaleza de sus componentes. El alumnado podrá llevar a cabo observaciones de cambios de estados, texturas, colores y aromas producidos en la materia. Para la adaptación de esta actividad hemos empleado una variedad de alginato dental denominada Phase Plus, de la compañía Zhermack. Se trata de un alginato cromático que al mezclar el polvo con agua cambia de color drásticamente. El polvo rosáceo inicial toma una coloración violeta muy intensa una vez que se ha convertido en gel. Al cabo de un minuto aproximadamente, la coloración comienza a tornar a rosa, hasta que finalmente se convierte en goma rígida, volviendo a ser blanco. Este tipo alginatos se emplean habitualmente en el ámbito odontológico, conteniendo en su fórmula componentes aromáticos que expidan olores agradables a clorofilas, mentas y otros tipos de frutas.

Por otra parte, el manejo de la escayola, como una materia de reproducción para los moldes de alginato, también ofrece la posibilidad de experimentar y observar cambios drásticos con la obtención de una sustancia sólida, a partir de la mezcla de agua y polvo. Para las personas que se inician en el manejo de estos materiales, los cambios cromáticos, de textura y solidez, tanto del alginato como de la escayola, resultan extremadamente llamativos. En el desarrollo de la experiencia, junto a los cambios y transformaciones que se producen en los materiales, hay que añadir la espectacularidad de los resultados. Esta variedad de alginato dental y la escayola, usados para llevar a cabo un vaciado del natural, proporcionan resultados sorprendentes y eficaces. En pocos minutos podemos obtener reproducciones hiperrealistas, copias muy exactas de objetos o de partes del cuerpo humano. Este gran realismo de las reproducciones realizadas por medio de moldes de alginato tiene el atractivo visual y emocional que Walter Benjamin (2003) analizó con su teoría de la mímesis en el libro La obra de arte en la época de su reproductibilidad técnica.

\section{Preparación de la actividad. Lugar, materiales e instrumentos necesarios}

El aula en la que se ha desarrollado el taller pertenece a las asignaturas de tecnología. Este espacio fue asignado para esta actividad al estar provisto de grifos y piletas para el uso de agua durante el proceso creativo. Todas las mesas se colocaron juntas en el centro del aula a modo de una gran mesa rectangular, para que tanto alumnado como profesorado tuviéramos espacio suficiente para manipular los materiales. Las principales herramientas y materiales con las que se desarrolla la actividad son el alginato como material de moldeo, un recipiente en el que verter el alginato e introducir nuestra mano para obtener su registro y la escayola, como materia de reproducción con la que llenamos el hueco que deja nuestra mano.

Para obtener una mezcla gelatinosa homogénea es importante seguir las indicaciones del fabricante de cada variedad de alginato. No obstante, la mezcla puede efectuarse sin problemas empleando polvo y agua a partes iguales. Lo 
fundamental, es depositar el polvo en el recipiente y en segundo lugar verter el agua. Procediendo en distinto orden, el polvo quedaría flotando en la superficie y la mezcla no sería posible. Para un correcto mezclado, se emplean movimientos firmes, rápidos y continuos. Al contrario que el alginato, para la preparación de la escayola, primero se vierte el agua. Después, se aplica el polvo al agua de forma extendida y espolvoreada, asegurándonos de que no caen grumos en la mezcla. Sabremos que hemos aplicado suficiente escayola al agua cuando esta forme una pequeña isla en el centro del recipiente. A continuación, esperamos unos minutos hasta que se aprecie que el polvo está totalmente empapado. Es en ese momento cuando removemos suavemente con la mano para unificar la mezcla y asegurarnos de que no hay grumos en el recipiente.

Con el fin de que cada alumno tuviera un recipiente donde verter el alginato y posteriormente introducir su mano, se han construido cilindros con acetato de 500 micras (uno por cada persona participante), de 13 a 15 centímetros de diámetro y 20 centímetros de profundidad, en los que se ha vertido el alginato en estado gel. Pueden usarse también recipientes improvisados de plástico tales como botellas o garrafas cortadas a la mitad. Estos cilindros de plástico hacen las veces de madreforma, cuya función es asegurar la forma del molde de alginato. Se ha utilizado venda de escayola para la confección de otros modelos de madreforma en casos en los que el alumno no adaptaba su mano al espacio del recipiente de acetato.

Otros instrumentos que son necesarios para romper la madreforma o el recipiente de plástico, una vez que ha fraguado la escayola que se ha vertido la escayola en el molde de alginato, son un cúter o unas tijeras, que en cualquier caso son materiales escolares habituales.

\section{Descripción de la sesión}

Se trata de una actividad participativa y colectiva de introducción al uso de técnicas escultóricas de moldeo y vaciado del natural en la que los alumnos se involucran en el manejo de materiales artísticos. Para dar inicio a la sesión, se hizo una breve presentación colectiva de profesores y alumnado, con el propósito de establecer un vínculo de confianza dentro del aula. A continuación, se mostraron algunas imágenes de obras escultóricas contemporáneas realizadas con el mismo procedimiento de moldeo con alginato que ellos iban a emplear para reproducir su mano. Se trata de una introducción a la educación visual y plástica, que derivan en un aprendizaje estético del objeto que ellos mismos van a construir. Es una actividad creativa en la que profesores y alumnos están incluidos en el proceso, ya que ha sido necesario diseñar estrategias de transmisión muy sensibles para una completa asimilación de conceptos estéticos. (Grasso, 2018, p.83).

La sesión ha sido monitorizada por varios profesores, entre las que se incluyen dos profesoras del centro con gran experiencia con este grupo de alumnado. La 
presencia de las profesoras nos ha ayudado a corregir y simplificar ciertos modos de la comunicación, afianzando la recepción de contenidos y ofreciendo la confianza al alumnado ante personas desconocidas que llegan por primera vez a su aula.

Habiendo establecido el nivel de confianza suficiente, se explica al alumnado que la sesión consiste en introducir su mano en el cubilete con alginato en estado gel para dejar su huella. Al cabo de unos minutos sacan la mano del alginato que se ha endurecido sin dejar de ser flexible. Después se vierte la escayola en cada uno de los moldes, esperando nuevamente unos minutos hasta que ésta endurezca. El alumnado es el encargado de romper el molde para extraer la reproducción de su mano en escayola. Son procesos rápidos, que monitorizados, son fáciles de comprender, en los que el alumno encuentra estímulo visual y manipulativo al experimentar la fresca temperatura y la viscosa textura de la materia gelificada, el cambio de color, de violeta a rosa y el cambio de estado, de gel a goma.

Se hizo una demostración con una de las profesoras que nos acompañaban, que introdujo su mano en el recipiente lleno de alginato y esperó a que fraguase. Cuando la profesora extrajo su mano lentamente del recipiente, el alumnado pudo contemplar la huella y la impronta de la piel en las paredes del molde (el negativo). Seguidamente, el molde se llenó de escayola mientras todos participábamos dialogando acerca de formas, la idea del concepto de "moldes" que ellos tenían y como se imaginaban la realización de una escultura. Al fraguar la escayola completamente, la profesora comenzó a romper el molde alginato para extraer la reproducción de su propia mano. La perplejidad de los alumnos se hizo patente al poder tocar la mano de su profesora convertida en escayola. Nunca antes habían podido contemplar una construcción plástica tan realista como la realizada con alginato. Para reforzar la comprensión del procedimiento, se visionaron de nuevo las imágenes de esculturas contemporáneas realizadas con esta técnica, que se quedaron de acompañamiento visionadas en el proyector durante la actividad para incentivar la participación. Uno de nuestros objetivos fue incrementar la confianza en el uso de materiales y que ellos mismos comprobaran que este producto se puede tocar y manipular sin el menor problema (Cuadrado et al. 1998).

La mezcla de alginato y agua se realizó en un cubo, removiendo gran cantidad de materia con ayuda de una hélice de pintura adaptada a un taladro, consiguiendo una mezcla homogénea y suficiente para todos los participantes. El proceso de mezcla se llevó a cabo en el centro del aula para que todos pudieran observar cómo se manipulaba la materia mientras explicábamos cual iba a ser el siguiente paso. Las profesoras presentes en el aula nos ayudaron a establecer el nivel de información detallada que era posible facilitar al alumnado. La información fue clara y directa, en ocasiones de forma reiterativo-informativa, generando situaciones de preguntarespuesta e iniciando etapas de actuación para que el foco de atención esté activo en todo momento (Allemani y Villuendas, 2004, p 183). 
Durante el proceso, uno de los alumnos con síndrome de Down y otro con trastorno de espectro autista no accedieron a introducir la mano en el recipiente hasta no ver el resultado de los demás. Las profesoras, junto con dos compañeros que estaban a su lado realizando la actividad, consiguieron transmitir a estos el ánimo para desempeñarla, siempre desde un punto de vista motivacional y participativo, dado que no se trata de una actividad limitante que pudiera desembocar en frustración (Dito et al. 2004).

Con la mano introducida en el recipiente lleno de alginato en estado gel, el alumnado queda asombrado al notar que la materia gelificante, en breves instantes comienza a endurecer. Analizan en todo momento los cambios procesuales del alginato. Es un momento de experimentación manipulativa muy intensa, porque incluso ellos mismos advierten del cambio de estado de la materia. Todos extraen con facilidad e independencia la mano del molde de alginato, para ver los minuciosos registros que su piel ha dejado en la materia. En el trascurso de tiempo comprendido entre la mezcla de la escayola, vertido en el molde y fraguado, se repartieron fragmentos sobrantes del alginato fraguado utilizado en la demostración inicial en la que participó la profesora, para que tocaran y manipularan la materia con la que habían trabajado.

El nuevo objetivo es romper el molde de alginato con mucho cuidado para no causar daño a la reproducción. Lo ideal para la realización de un taller basado en la confección de moldes de alginato, es que sea el propio alumno el que desarrolle todas las fases de la actividad. Este hecho hizo que desde el principio del vertido de escayola, comprendieron que esa iba a ser la reproducción de su mano (López Melero, 2013).

El momento de romper el molde de alginato fue el de mayor plenitud. Fue el alumnado el que se encargó de romper su propio molde en pequeños trozos. Ninguno de ellos esperaba una reproducción tan perfecta y fidedigna de su propia mano (figura 2) y (figura 3).

Para estos procesos manipulativos se prestó especial atención a una de las alumnas, afectada por un cuadro de hemiplejia, que consiste en una lesión cerebral que provoca alteraciones y deficiencias motoras. La naturaleza de los materiales empleados presenta gran versatilidad de uso en inclusión de actividades monitorizadas, sin la existencia de ninguna contrariedad basada en durezas o esfuerzos a los que alumnos con dificultad motora moderada no puedan enfrentarse (Galligó et al., 2003). 


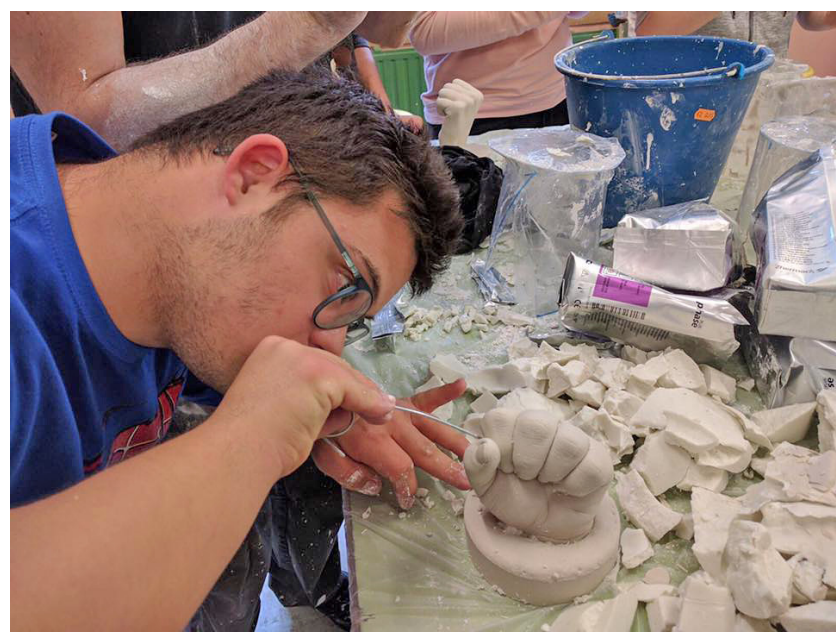

Figura 2. Alumno extrayendo los restos de alginato de la reproducción de su mano en escayola.

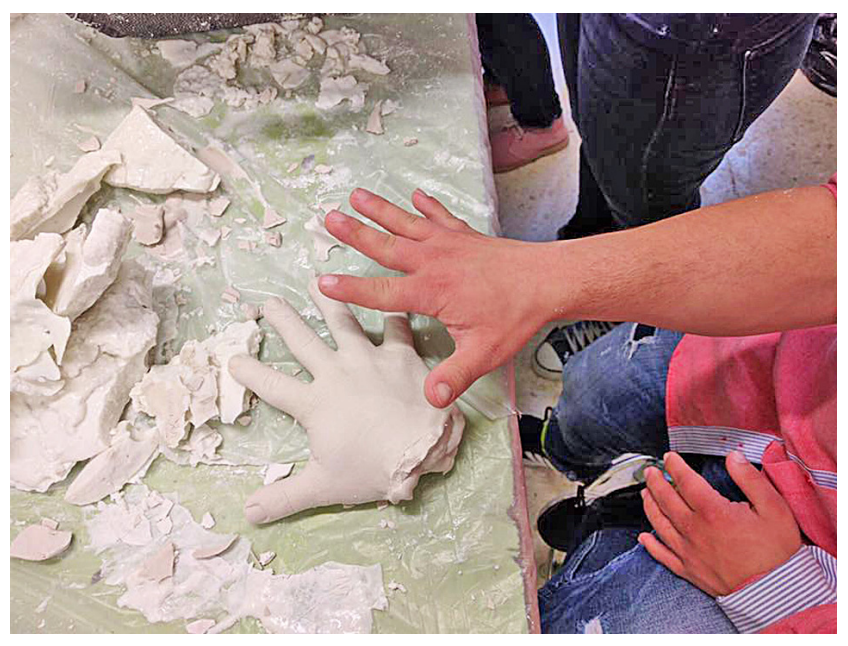

Figura 3. Reproducción de mano de escayola realizada por alumno con síndrome de down a partir de fase de moldeo con alginato dental.

\section{Discusión}

Al tratarse de un grupo reducido es factible desarrollar un modelo de atención personalizado para cada alumno adaptado al tipo de dificultad que tenga, pudiendo idear diferentes objetivos para la realización de este tipo de actividades.

Es necesario cuidar una comunicación verbal clara y directa al tratarse de materiales y técnicas procesuales en los que no resulta fácil mantener una comprensión global del proceso y en ocasiones, una total comprensión de los resultados obtenidos. El lenguaje ha de ser muy simplificado para que puedan comprender los mecanismos plásticos sin la necesidad de emplear tecnicismos en las explicaciones. 
En función del nivel cognitivo de cada alumno, se emplearán argumentaciones más adaptadas a sus necesidades, a ser posible, que sean lo más fieles a la realidad para que poco a poco el alumnado realice procesos perceptivos más complejos (Luckasson et al., 2002).

Las dificultades que pudieran surgir tanto a nivel técnico como a nivel colectivo dentro del aula, se solventan ofreciendo elementos activos que se basen en el "aquí y ahora", destacando el "qué" y el "cómo" en lugar de ofrecer interrogantes (por qué).

\section{Conclusión}

Es necesario promover la relación entre el alumnado dentro del aula. Al ver que los objetivos se cumplen de manera satisfactoria, la autoestima aumentará de manera significativa a nivel colectivo y personal. La adaptación de actividades plásticas como la descrita, llevadas a cabo paso a paso, ayudan a la estimulación cognitiva y a la integración en el grupo. El hecho de que todos lograran un objetivo con la resolución de una actividad común para la obtención de su reproducción escultórica, promueve la integración de la persona en un círculo colectivo. Observando la predisposición y el gran entusiasmo del alumnado frente a este tipo de sesiones, percibimos la necesidad de incentivar la cultura artística en los centros de enseñanza como medio integrador. Existe la necesidad de que toda persona consiga reforzar o completar su sentido artístico y estético, es por ello, que a día de hoy es necesario un acercamiento a las aulas aun mayor, de las artes tanto visuales como plásticas (Huerta, Domínguez y Barbosa, 2017).

En esta actividad queda muy marcada la experiencia emocional de los alumnos, aumentando la autoestima por medio de la construcción plástica. El mecanismo comprensivo y perceptivo que configuran es que es su mano la que sale del molde y que son ellos los que la han construido, reforzando de esta manera su propia confianza personal. Gracias al desarrollo de este tipo de actividades en grupo, se consigue que el aula se convierta en un lugar de aprendizaje cooperativo y solidario (Fig. 5. Reproducción de mano en escayola realizada por uno de los alumnos con síndrome de down) (Temprado 2009, p 141).

Es muy importante el dominio del uso y preparación de materias por parte del profesorado, para hacer de esta experiencia una actividad en la que el margen de error o posibilidad de que el resultado sea erróneo sea casi nula. El éxito en la consecución de objetivos aumenta la tolerancia de frustración en el momento de enfrentarse a determinados momentos y estímulos reales, dentro y fuera de las aulas. El desarrollo de habilidades manipulativas y perceptivas con este grupo de personas puede promover la capacitación para desempeñar determinadas actividades laborales (Urtado Maceo, 2018). 
Es necesario que la información llegue de manera clara y sin interferencias derivadas de otros temas para poder ofrecer situaciones en las que el alumnado pueda manifestar sus experiencias y aprendizajes previos. En este caso, esta situación conduce a una satisfacción generada por un aumento de la autoestima al experimentar que la reproducción de su mano en escayola ha sido un trabajo realizado por ellos mismos. Este hecho manifiesta que el material esté adaptado a la consecución de procesos técnico-plásticos y al propio alumnado (figura 4).

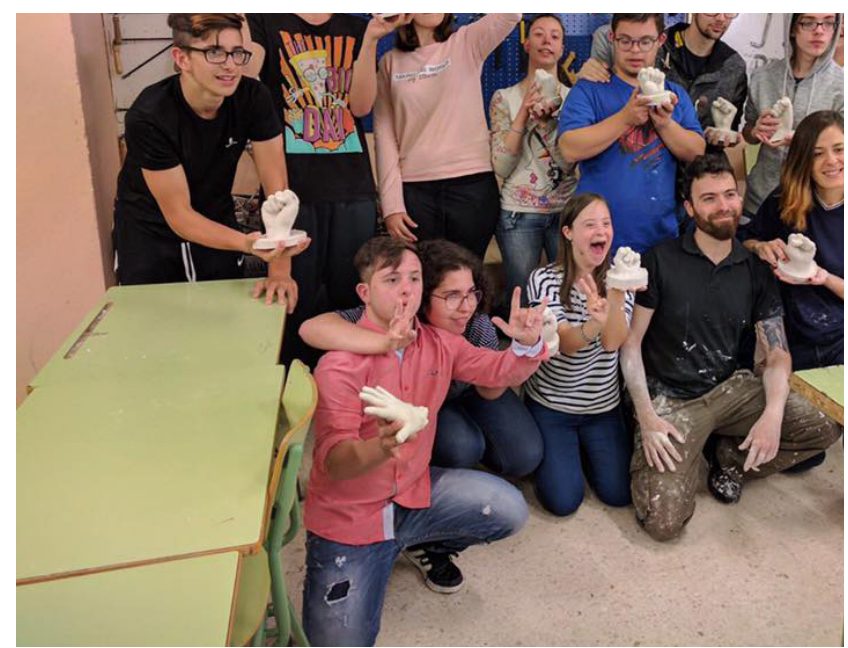

Figura 4. Conjunto de alumnos del Programa Específico de Formación Profesional Básica, del instituto de enseñanza secundaria Los Cerros, Úbeda.

\section{Referencias}

Alemani Arrebola, I. y Villanueva Giménez, M. D. (2004). "Las Actitudes del Profesorado hacia el Alumnado con Necesidades Especiales". En Convergencia. Revista de Ciencias Sociales. (S.V.)34,pp. 183-215. México: Universidad Autonómica del estado de México.

Cuadrado, I., Davara, L., López, M. y Murillo, M. (1998). Alumnos con necesidades educativas especiales. Cáceres: Servicio de publicaciones de la Universidad de Extremadura.

Delgado, J. (2015). Apariencia y juego. La teoría de la imitación de Walter Benjamin. Logos. Anales de Seminario de Metafísica. 48 (S.N.) pp. 57-82. http//:dx. doi.org/10.5209/rev_ASEM.2015.v48.49274 Madrid, Universidad Complutense de Madrid.

Dito, E., Prieto, L. y Yuste, V. (2004). El ocio y tiempo libre como claves integradoras en el deficiente mental. Revista interuniversitaria de formación del profesorado. 18,2, pp. 183-187. Zaragoza: (AUFOP). 
ÁNGELES / Las técnicas escultóricas de reproducción como medio de integración para alumnado con discapacidad

Galligó, M., Galligó, T., Requena, E., Saumell, E. y Torres, J. (2003). El aprendizajey sus trastornos. Consideraciones psicológicas y pedagógicas. Barcelona: Ediciones CEAC.

Grasso, M. (2018). Educación por el Arte y Formación Docente: Repensar el mandato fundacional disciplinador para transformar la escuela. EARI. Educación Artística Revista de Investigación. 9, 81-94. Valencia: Universitat de València.

Huerta, R., Dominguez, R. y Barbosa, A. M. (2017). Investigar para educar en diseño y otras urgencias de la Educación Artística. EARI. Educación Artística Revista de Investigación. 8, 10-23. Valencia: Universitat de València.

López Melero, M. (2013). El proyecto Roma: una experiencia de educación en valores. Málaga: Ediciones aljibe.

Luckasson, R., Borthwick-Duffy, S., Buntinx, W.H.E., Coulter, D., Craig, E., Reve, A., Schalock, R., Snell, M., Spitalnik, D., Spreat, S. y Tasse, M. (2002). Mental retardation: Definition, classification and systems of support. American Association of Mental Retardation: Washington D.C.

Temprado Bernal, M. (2009). Ventajas del Aprendizaje Cooperativo para la Socialización de los Alumnos con Necesidades Educativas Especiales. Revista Interuniversitaria de Formación del Profesorado, 65, (23'2), 137-150. Recuperado de http://sociales.redalyc.org/articulo.oa?id=27419063010

Schalock, R. (2009). La nueva definición de discapacidad intelectual, apoyos individuales y resultados personales. Siglo Cero. Revista Española sobre Discapacidad Intelectual. 40, 1, 22-39. Salamanca: Ediciones Universidad de Salamanca.

Urtado Maceo, O. (2008). Recursos pedagógicos para una vida adulta independiente en escolares con retraso mental moderado. Edusol. 24 (8), 40-46. Cuba: Centro Universitario de Guantánamo. 